\title{
Phenolic compounds and bioactivity of Scorzonera pygmaea Sibth. \& Sm. aerial parts: In vitro antioxidant, anti-inflammatory and antimicrobial activities
}

\author{
Hasan Șahin $1,2,3$ (D), Aynur Sarıำ (D), Nurten Özsoy ${ }^{4}$ (D), Berna Özbek Çelik ${ }^{5}$ (D) \\ 'Istanbul University, Faculty of Pharmacy, Department of Pharmacognosy, Istanbul, Turkey \\ ${ }^{2}$ Istanbul University, Graduate School of Health Sciences, Istanbul, Turkey \\ ${ }^{3}$ Dicle University, Faculty of Pharmacy, Department of Pharmacognosy Diyarbakır, Turkey \\ ${ }^{4}$ Istanbul University, Faculty of Pharmacy, Department of Biochemistry, Istanbul, Turkey \\ ${ }^{5}$ Istanbul University, Faculty of Pharmacy, Department of Pharmaceutical Microbiology, Istanbul, Turkey
}

ORCID IDs of the authors: H.S. 0000-0002-8325-8116; A.S. 0000-0001-8116-7053; N.0̈. 0000-0002-2419-9128;

B.Ö.C.. 0000-0001-8909-8398

Cite this article as: Sahin, H., Sari, A., Ozsoy, N., \& Ozbek Celik, B. (2020). Phenolic compounds and bioactivity of Scorzonera pygmaea Sibth. \& Sm. aerial parts: In vitro antioxidant, anti-inflammatory and antimicrobial activities. Istanbul Journal of Pharmacy, $50(3), 294-299$

\begin{abstract}
Background and Aims: Scorzonera L. genus contains several medicinal and edible plants. Both roots and aerial parts of Scorzonera species are used. S. pygmaea is endemic to Turkey. In a previous study, nine phenolic compounds were reported from the roots of the plant alongside certain biological activities. The current study was designed to investigate the aerial parts of the plant in the same manner and compare the potentials of the two parts.

Methods: Chromatographic and spectroscopic methods were used to isolate and identify the phenolics. Total phenolic contents were determined by Folin-Ciocalteu method. FRAP assay, anti-LPO, scavenging DPPH, ABTS and superoxide radicals were employed to evaluate the antioxidant activity. COX inhibition test and micro broth dilution technique were used for antiinflammatory and antimicrobial activities, respectively.

Results: Seven phenolic compounds; thunberginol C (1), protocatechuic acid (2), chlorogenic acid methyl ester (3), cudrabibenzyl A (4), scorzocreticin (5), scorzocreticoside I (6) and II (7) were purified. All the compounds are new for the aerial parts of the plant and 2 is new for the genus. The aerial parts showed a high antioxidant capacity which correlated with its phenolic content. COX inhibitory activity was found to be lower compared to Indomethacin. Weak antimicrobial activity was determined against Staphylococcus aureus and S. epidermidis.

Conclusion: Aerial parts possess significant/infrequent phenolics and the ethyl acetate (EtOAc) fraction of the ethanol extract is the most promising fraction for isolating these compounds. Phenolic compositions of aerial parts and roots are very similar. However, aerial parts can be a better rich source of natural antioxidants with protocatechuic acid and higher antioxidant potential.
\end{abstract}

Keywords: Scorzonera pygmaea, phenolics, antioxidant, protocatechuic acid

\section{INTRODUCTION}

There are about 160 Scorzonera (Asteraceae) species in the world. Turkey is currently host to 52 species and 31 of them are endemic (Coşkunçelebi, Makbul, Gültepe, Okur, \& Güzel, 2015). Members of the genus are both medicinal and edible plants. S. hispanica L., a related species, is used in several countries' cuisines and commonly known as black salsify or viper's grass. Although 
Şahin et al. Phenolic compounds and bioactivity of Scorzonera pygmaea Sibth. \& Sm. aerial parts: In vitro antioxidant, anti-inflammatory and antimicrobial activities

this species is cultivated as a vegetable in some regions of Europe, Scorzonera species are rather considered as forgotten vegetables in the world due to their disappearing culinary uses over time. Many records show the traditional usage of Scorzonera species for the treatment of gout, pain, rheumatism, injuries, diabetes, diarrhoea, infertility, gastric disorders, pulmonary oedema and hypertension (Baytop, 1999; Dalar, Mukemre, Unal, \& Ozgokce, 2018; Polat, 2019; Tsevegsuren et al., 2007). There are several phytochemical investigations on the genus. Previously, flavonoids (Acıkara, Ergene Öz, Bakar, Saltan Çitoğlu, \& Nebioğlu, 2017), bibenzyl derivatives (Zidorn, Ellmerer-Müller, \& Stuppner, 2000), benzyl phthalates (Sarı, 2010), coumarins (Harkati, Akkal, Bayat, Laouer, \& Franca, 2010), dihydroisocoumarins (Sarı et al., 2007), phenolic acid derivatives (Sarı, Şahin, Özsoy, \& Özbek Çelik, 2019), lignans - neolignans (Bader, De Tommasi, Cotugno, \& Braca, 2011), sesquiterpenes (Yong Jin Yang et al., 2016) and triterpenes (O. B. Acıkara et al., 2012) were determined in the genus.

With regard to black salsify or other Scorzonera species; roots are more conceivable but it's known that the fresh leaves of these plants are eaten as a vegetable in Turkey and some other countries in Europe too (Baytop, 1999; Şenkardeş, Bulut, Doğan, \& Tuzlacı, 2019; Tsevegsuren et al., 2007). Even more so, the aerial parts of the genus are used as ethnomedicines against liver disorders, diabetes, headache, hypertension and infertility (Dalar et al., 2018; Singh \& Lal, 2008). Scorzonera pygmaea Sibth. \& Sm. is a perennial herb. It's endemic to West Anatolia and measures only $1.5-11 \mathrm{~cm}$ in height as its name signifies (Koyuncu, Yaylacı, \& Kuş, 2014). The roots of the plant were investigated in another study and nine phenolic compounds were reported along with certain biological activities (Şahin, Sarı, Özsoy, Özbek Çelik, \& Koyuncu, 2020). Thus, the aerial parts of S. pygmaea were subjected to this study in terms of phenolics and in-vitro bioactivity studies. Thereby, the evaluation of the significance of the aerial parts and comparison between potentials of the roots and aerial parts were aimed.

\section{MATERIALS AND METHODS}

\section{Plant material}

Flowered herba of S. pygmaea were collected from Eskişehir in July 2015 and identified by O. Koyuncu (Associate Prof.). A voucher specimen was deposited with the ESK 18397 number at Osmangazi University Herbarium (Eskişehir).

\section{Extraction, isolation and structure elucidation}

The aerial parts of S. pygmaea were air-dried by protecting direct sunlight and powdered. $2 \mathrm{~kg}$ of this powder was extracted using the maceration technique with ethanol. The macerate was concentrated with a rotary evaporator at $45^{\circ} \mathrm{C}$. A methanol/water (1:2) mixture was used to dissolve this macerate. Then the macerate was successively extracted with petroleum ether (yielded $46.8 \mathrm{~g}$ ), chloroform (yielded $4.1 \mathrm{~g}$ ), ethyl acetate (yielded $9.8 \mathrm{~g}$ ) and $n$-butanol (yielded $8.2 \mathrm{~g}$ ) respectively. $9 \mathrm{~g}$ of the ethyl acetate fraction was subjected to column chromatography (CC) $\left(\mathrm{CHCl}_{3} / \mathrm{MeOH} 100: 0,98: 2,96: 4,94: 6,92: 8,88: 12\right.$, 80:20, 70:30, 50:50, 0:100; silica gel) and 210 fractions (Fr) were obtained. Fr 8-16 was purified by CC (MeOH; Sephadex LH-20) and gave 47 further fractions (FFr). FFr 17-29 was subjected to preparative thin layer chromatography (TLC) (toluene/EtOAc/ $\mathrm{HCOOH}$ 7:4:1; silica gel) to afford 1 (7.1 mg). Fr 17-22 was purified by preparative TLC (toluene/EtOAc/HCOOH 5:4:1; silica gel) and gave 2 (15.0 mg). Fr 36-38 was further separated by preparative TLC (toluene/EtOAc/HCOOH 5:5:1; silica gel) to provide 3 (7.0 mg). Fr 56-68 was subjected to CC (MeOH; Sephadex $\mathrm{LH}-20$ ) and gave 50 further fractions (FFr). FFr 27-43 was purified with preparative $\mathrm{TLC}\left(\mathrm{CHCl}_{3} / \mathrm{MeOH} 75: 25\right.$; silica gel) to afford pure compounds 4 (20 mg), 5 (20 mg) and 6 (10 mg). Fr 71-77 was purified by $\mathrm{CC}(\mathrm{MeOH}$; Sephadex LH-20) and gave 64 further fractions (FFr). FFr 10-15 was purified with preparative TLC ( $\mathrm{CHCl}_{3} / \mathrm{MeOH} 70: 20$; silica gel) to yield pure 7 (8.3 mg).

\section{Chemicals, solvents and instrumental details}

6-hydroxy-2,5,7,8-tetramethylchromane-2-carboxylic acid (Trolox), $\beta$-nicotinamide adenine dinucleotide reduced $(\beta-N A D H)$, Nitroblue tetrazolium (NBT), 2,2'-Azino-bis(3-ethylbenzothiazoline-6-sulfonic acid) diammonium salt (ABTS), butylated hydroxytoluene (BHT), and rutin were obtained from Fluka (Buchs, Switzerland). Phenazine methosulphate (PMS), 2,2-diphenyl-1-picryl-hydrazyl (DPPH), soybean L-aphosphatidylcholine type IV-S, gallic acid and ascorbic acid were obtained from Sigma- Aldrich (St. Louis, MO, USA). Other chemicals were obtained from Merck (Darmstadt, Germany) including 2,4,6-tripyridyl-s-triazine (TPTZ), trichloroacetic acid (TCA), thiobarbituric acid (TBA) and ferric chloride. Remaining reagents and solvents were analytical grade. Shimadzu UV 1700 Pharmaspec UV-VIS, Bruker Avance III $500 \mathrm{MHz}$ and Thermo Finnigan LCQ Advantage MAX (ESI) were employed for acquiring UV, NMR and ESI-MS spectrums.

\section{Total phenolic content determination}

A method using the Folin-Ciocalteu reagent was chosen for determining the total phenolic contents of the fractions (Slinkard \& Singleton, 1977). Gallic acid equivalents were calculated (GAE/g fraction) for expressing the results.

\section{Antioxidant activity assays}

Five different methods were used to evaluate the antioxidant potential of the fractions. Rutin was used as standard for all assays. The $\mathrm{EC}_{50}$ values are given where applicable. The scavenging activity of ABTS radical was expressed as both $\mathrm{EC}_{50}$ and Trolox equivalent. The results are given as $\mathrm{mM}$ Trolox equivalents (Re et al., 1999). The DPPH scavenging activities of the fractions were measured by a procedure described by Brand-Williams et al. (Brand-Williams, Cuvelier, \& Berset, 1995). The nitroblue tetrazolium reduction method was employed to evaluate the effect of the fractions on producing superoxide radicals (Nishikimi, Rao, \& Yagi, 1972). The determination of inhibitory activities of the fractions on lipid peroxidation and the ferric reducing antioxidant power assay (FRAP) were conducted according to Duh et al. (Duh, Tu, \& Yen, 1999) and Benzie and Strain (Benzie $\&$ Strain, 1996) respectively. The results are given as $m M ~ F e+2 / L$ and calculated with a standard curve of iron sulfate heptahydrate in FRAP assay.

\section{Antimicrobial activity}

The antimicrobial potentials of the fractions were evaluated using the micro broth dilution technique (CLSI, 2000, 2006). Escherichia coli ATCC 8739, Candida albicans ATCC 10231, Pro- 
teus mirabilis ATCC 14153, Staphylococcus aureus ATCC 6538, Klebsiella pneumoniae ATCC 4352, Staphylococcus epidermidis ATCC 12228, Enterococcus feacalis ATCC 29212 and Pseudomonas aeruginosa ATCC 1539 were used for testing the activity. All microorganisms were purchased from the American Type Culture Collection (ATCC, Manassas, VA, USA).

\section{Anti-inflammatory activity}

An enzyme immunoassay kit (Cayman 560131) was employed for determination of COX inhibitory activity for the fractions. The assay was conducted according to the kit's protocol.

\section{Statistical analysis}

The results are expressed as means of three replicates \pm standard deviation. GraphPad Prism version 7.00 was used to perform statistical comparisons with Student's t-test $(p<0.05)$.

\section{RESULTS AND DISCUSSION}

Isolation studies conducted on ethyl acetate fraction of S. pygmaea aerial parts yielded four dihydroisocoumarins [thunberginol C (1), scorzocreticin (5), scorzocreticoside I (6) and scorzocreticoside II (7)], two phenolic acid derivatives [protocatechuic acid (2), chlorogenic acid methyl ester (3)] and one bibenzyl derivative [cudrabibenzyl A (4)] (Figure 1). Structure elucidation of the compounds 1 (Toshikawa et al., 1992), 2 (Chang et al., 2009), 3 (Sarı, 2012; Zhu, Dong, Wang, Peng, \& Luo, 2005), 4 (Nguyen, Juvik, Øvstedal, \& Fossen, 2014), 5, 6 and 7 (Paraschos, Magiatis, Kalpoutzakis, Harvala, \& Skaltsounis, 2001) was achieved by interpreting their spectroscopic data (UV, proton NMR, carbon NMR, HSQC, HMBC and ESI-MS) and comparing them with the relevant literature.

All reported compounds are new for the aerial parts of S. pygmaea. The phytochemical composition of the subaerial and aerial parts of the plant seems to be very similar in terms of phenolic compounds (Şahin et al., 2020). Apart from protocat- echuic acid, the other compounds were previously identified in the root extract of the plant. Protocatechuic acid, which is shown to be a metabolite of some polyphenols and a significant contributor to the alleged benefits of anthocyanins, is very common in several food plants (Vitaglione et al., 2007). This study is the first report to show a Scorzonera species containing protocatechuic acid. This compound might be considered as rare in the family Asteraceae due to its limited distribution with a few genera like Centaurea L. and Rhaponticum Hill (Baykan-Erel, Bedir, Khan, \& Karaalp, 2010; Kokoska \& Janovska, 2009). A new compound (Cudrabibenzyl A) for the family Asteraceae and another (Thunberginol C) new for the genus Scorzonera are reported in this study excluding the report for the roots of the same plant. Scorzocreticin and scorzocreticoside II were found in only S. cretica Willd. (an endemic of Crete and South Aegean which is commonly used in meat dishes) and S. pygmaea by now (Paraschos et al., 2001; Şahin et al., 2020). However, scorzocreticoside I is a common compound in S. cretica, T. porrifolius L. (white salsify) and S. pygmaea (Zidorn et al., 2005). Phenolic acids, such as quinic acid, caffeic acid and ferulic acid esters have a high incidence in the genus Scorzonera. Chlorogenic acid methyl ester was previously isolated from S. latifolia and S. veratrifolia Fenzl (Sarı, 2010, 2012). These esters comprise a large group of natural polyphenols in the human diet which are counted in the phytochemicals responsible for the beneficial effects of vegetables, fruits and beverages (Liang \& Kitts, 2016).

The total phenolic contents of ethyl acetate, chloroform and n-butanol fractions obtained from the ethanol extract of the S. pygmaea aerial parts were determined. Values are gallic acid equivalents and $124.3 \pm 4.09 ; 26.8 \pm 2.33$ and $34.49 \pm 3.44$ $\mathrm{mg} / \mathrm{g}$ fraction, respectively. The petroleum ether fraction failed to extract any phenolic compounds. These results indicate that the aerial parts have a higher amount of total phenolic content than the roots (Şahin et al., 2020).<smiles>O=C1OC(c2ccc(O)cc2)Cc2cc(O)cc(O)c21</smiles>

2<smiles>O=C(O)c1ccc(O)c(O)c1</smiles>

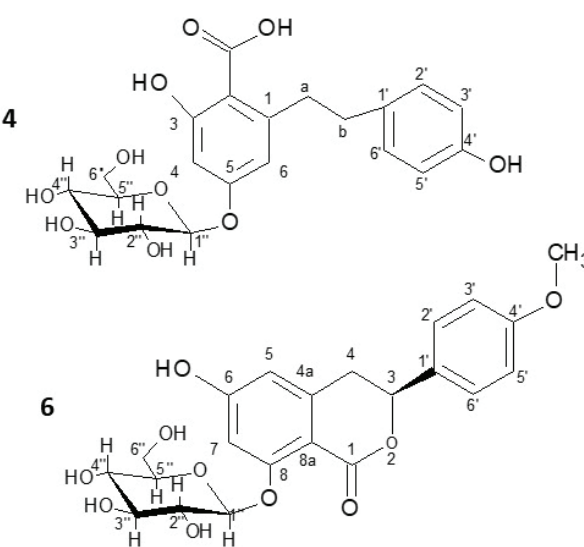

3<smiles>COC(=O)C1(O)CC(O)C(O)[C@@H](OC(=O)/C=C/c2ccc(O)c(O)c2)C1</smiles>

5<smiles>COc1ccc(C2Cc3cc(O)cc(O)c3C(=O)O2)cc1</smiles>

7

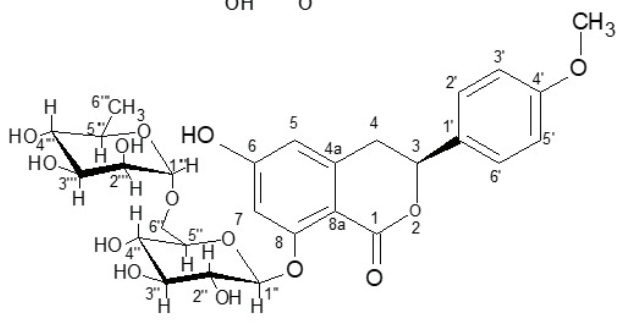

Figure 1. Structures of the compounds isolated from S. pygmaea aerial parts. 
Şahin et al. Phenolic compounds and bioactivity of Scorzonera pygmaea Sibth. \& Sm. aerial parts: In vitro antioxidant, anti-inflammatory and antimicrobial activities

The antioxidant activity results are given in Table 1. The highest efficiency rates of extracting phenolic compounds and the highest antioxidant potential were observed in the EtOAc fraction. The most scavenged radical by all fractions was found to be superoxide, which might be explained by the relatively weak nature of this radical. However, scavenging activity of superoxide is much desired because it is a widespread precursor of several reactive oxygen species (Phaniendra, Jestadi, \& Periyasamy, 2015). EtOAc fraction of the aerial parts showed better or nearly equal activities compared to rutin in LPO, SO and FRAP assays. Moreover, the EtOAc fraction of the aerial parts showed stronger antioxidant effect than the same fraction of the roots in all the methods apart from the scavenging activity of DPPH (this was almost equal). This might be due to its relatively high total phenolic content. Compared to the roots, it is observed that the aerial parts are more promising for antioxidant potential (Şahin et al., 2020). There have been a considerable number of antioxidant studies conducted on Scorzonera species (Acıkara et al., 2017; Athmouni, Belghith, Bellassouad, Feki, \& Ayadi, 2015; Milella, Bader, De Tommasi, Russo, \& Braca, 2014; Nasseri, Sharifi Bigy, Allahresani, \& Malekaneh, 2015; Sarı et al., 2019; Şahin et al., 2020; Tsevegsuren et al., 2007; Wang,
Wray, Tsevegsuren, Lin, \& Proksch, 2012; Y. J. Yang et al., 2013). These studies are in accordance with the current results of $S$. pygmaea as they displayed potent antioxidant activity pointing to the phenolics as responsible substances.

Antimicrobial activity results of the fractions and standards are given in Table 2. No activity was observed against gram negative bacteria and yeast strain; however, a weak activity was determined against gram positive bacteria. These results are in accordance with the limited available data about antimicrobial activity of Scorzonera species (Sarı, Özbek, \& Özgökçe, 2009; Şahin et al., 2020; Christian Zidorn et al., 2002).

The results of COX inhibition (a well-known anti-inflammatory mechanism) assay are given in Table 3. All fractions showed no anti COX-1/2 activity comparable with that of indomethacin. Considering the traditional anti-inflammatory usage of Scorzonera species and anti-inflammatory compounds of S. pygmaea (protocatechuic acid, chlorogenic acid methyl ester (Lende et al., 2011; Liang \& Kitts, 2016)), different methods such as inhibition of pro-inflammatory cytokines or in-vivo models might be used for evaluating ani-inflammatory potential of the plant.

Table 1. Antioxidant potential of S. pygmaea aerial parts.

\begin{tabular}{|c|c|c|c|c|c|c|}
\hline & \multicolumn{4}{|c|}{$E C_{50}{ }^{A}$} & \multirow{2}{*}{ TEAC $^{\mathrm{B} *}$} & \multirow{2}{*}{ FRAP ${ }^{c *}$} \\
\hline & Anti-LPO & so & DPPH & ABTS & & \\
\hline PE & - & - & - & - & - & - \\
\hline $\mathrm{CHCl}_{3}$ & $6.60 \pm 0.46^{a}$ & $0.48 \pm 0.01^{a}$ & $8.40 \pm 0.22^{\mathrm{a}}$ & $6.66 \pm 0.40^{a}$ & $0.782 \pm 0.04^{\mathrm{a}}$ & $0.957 \pm 0.030^{a}$ \\
\hline EtOAc & $0.92 \pm 0.02^{\mathrm{b}}$ & $0.46 \pm 0.02^{\mathrm{a}}$ & $1.24 \pm 0.02^{\mathrm{b}}$ & $1.09 \pm 0.12^{b}$ & $1.856 \pm 0.06^{\mathrm{b}}$ & $2.774 \pm 0.018^{b}$ \\
\hline $\mathrm{BuOH}$ & $7.79 \pm 0.42^{c}$ & $1.42 \pm 0.01^{b}$ & $5.21 \pm 0.11^{c}$ & $8.63 \pm 0.14^{c}$ & $0.484 \pm 0.01^{c}$ & $0.698 \pm 0.037^{c}$ \\
\hline Rutin & $0.72 \pm 0.02^{d}$ & $0.53 \pm 0.03^{a}$ & $0.142 \pm 0.02^{d}$ & $0.61 \pm 0.03^{d}$ & $2.113 \pm 0.04^{\mathrm{d} \star \star}$ & $2.864 \pm 0.04^{\mathrm{d} * *}$ \\
\hline $\begin{array}{l}{ }^{A} \mathrm{mg} / \mathrm{mL} \\
{ }^{\mathrm{B}} \text { Trolox } \\
{ }^{\mathrm{C}} \text { Ferrous } \\
\mathrm{PE} \text { (petr } \\
\text { aerial pa } \\
\text { Values W } \\
{ }^{*} \text { Concen }\end{array}$ & $\begin{array}{l}\text { hts as } \mathrm{mmol} / \mathrm{L} \text { ( } \mathrm{n} \\
\text { uivalents as } \mathrm{mm} \\
\text { her), } \mathrm{CHCl}_{3} \text { (chlo } \\
\text { rent letters in the } \\
\mathrm{f} \text { the fractions: } 2\end{array}$ & $\begin{array}{l}{ }^{2+} / \mathrm{L}(\mathrm{mM}) \\
\mathrm{rm} \text { ), EtOAc (eth } \\
\text { ne column wer } \\
\mathrm{g} / \mathrm{mL},{ }^{\star \star} \text { Conce }\end{array}$ & $\begin{array}{l}\text { etate), } \mathrm{BuOH}(n-b \\
\text { hificantly ( } p<0.05 \\
\text { tion of rutin: } 1.25\end{array}$ & $\begin{array}{l}\text { ol) fractions we } \\
\text { ferent. } \\
\mathrm{mL}\end{array}$ & tained from ethano & rate of S.pygmaea \\
\hline
\end{tabular}

Table 2. MIC values of the fractions obtained from ethanol extract of S. pygmaea aerial parts and of the standards (mg/L)

\begin{tabular}{lccccc} 
Microorganisms & $\mathrm{PE}$ & $\mathrm{CHCl}_{3}$ & $\mathrm{AcOEt}$ & $\mathrm{BuOH}$ & Standards \\
\hline Staphylococcus aureus & - & - & 1250 & - & 1.2 (Cefuroxime-sodium) \\
Staphylococcus epidermidis & - & - & 78 & 1250 & 9.8 (Cefuroxime-sodium) \\
Enterococcus feacalis & - & - & - & - & 8.0 (Ampicilin-sodium) \\
Proteus mirabilis & - & - & - & - & 2.4 (Cefuroxime-sodium) \\
Pseudomonas aeruginosa & - & - & - & - & 2.4 (Ceftazidime pentahydrate) \\
Klebsiella pneumoniae & - & - & - & - & 4.9 (Cefuroxim-sodium) \\
Escherichia coli & - & - & - & - & 4.9 (Cefuroxime-sodium) \\
Candida albicans & - & - & - & - & 4.9 (Clotrimazole)
\end{tabular}




\section{Table 3. Results of anti-inflammatory studies}

\begin{tabular}{|lcc|}
\hline Fractions $(20 \mathrm{mg} / \mathrm{mL})$ & COX-1 & COX-2 \\
\hline PE & $69.76 \pm 3.74^{\mathrm{a}}$ & $44.94 \pm 4.80^{\mathrm{a}}$ \\
$\mathrm{CHCl}_{3}$ & $84.65 \pm 6.30^{\mathrm{b}}$ & $33.83 \pm 2.11^{\mathrm{b}}$ \\
EtOAC & $67.05 \pm 3.62^{\mathrm{a}}$ & $26.21 \pm 3.49^{\mathrm{c}}$ \\
BuOH & $36.06 \pm 3.08^{\mathrm{c}}$ & $26.21 \pm 2.41^{\mathrm{c}}$ \\
Indomethacin & $87.56 \pm 0.66^{\mathrm{a}}$ & $93.42 \pm 2.99^{\mathrm{d} \star *}$ \\
\hline
\end{tabular}

$\mathrm{PE}$ (petroleum ether), $\mathrm{CHCl}_{3}$ (chloroform), EtOAc (ethyl acetate), $\mathrm{BuOH}$ ( $n$-butanol) fractions were obtained from ethanol macerate of S.pygmaea aerial parts

Values with different letters in the same column were significantly $(p<0.05)$ different.

* The concentration was $12.5 \mu \mathrm{g} / \mathrm{mL}$, ** The concentration was 50 $\mu \mathrm{g} / \mathrm{mL}$

\section{CONCLUSION}

The aerial parts of S. pygmaea contain significant and infrequent phenolics. The EtOAc fraction of the ethanol extract is the most promising fraction for isolating these compounds. Some of these phenolics gain nutritional interest such as protocatechuic acid which is determined in the genus Scorzonera for the first time in the present study. The phenolic composition of the aerial parts is very similar to its roots. The aerial parts of S. pygmaea possess a potent and higher antioxidant capacity than its roots which might be derived from a higher amount of total phenolic content. Hence, the whole plant, especially the aerial parts, can be used as a source of natural antioxidants with a consequent impact on health benefits. No noteworthy result was observed for COX inhibition and antimicrobial potentials of the plant.

Peer-review: Externally peer-reviewed.

Author Contributions: Conception/Design of Study- A.S., H.Ş.; Data Acquisition- A.S., H.Ş., N.Ö., B.Ö.Ç.; Data Analysis/Interpretation- A.S., H.Ş., N.Ö., B.Ö.Ç.; Drafting Manuscript- H.Ş.; Critical Revision of Manuscript- A.S., H.Ş., N.Ö., B.Ö.Ç.; Final Approval and Accountability- A.S., H.Ş., N.Ö., B.Ö.Ç.; Technical or Material Support- A.S., H.Ş., N.Ö., B.Ö.Ç.; Supervision- A.S., H.Ş., N.Ö., B.Ö.Ç.

Conflict of Interest: The authors have no conflict of interest to declare.

Financial Disclosure: This study was financially supported by the Coordination Office of Lecturer Training Program of Istanbul University. (Grant number: 181.2015-DR-35/27-07)

Acknowledgement: The authors want to thank Onur Koyuncu for collecting and identifying the plant metarial.

\section{REFERENCES}

- Acıkara, O. B., Çitoglu, G. S., Dall'Acqua, S., Smejkal, K., Cvacka, J., \& Zemlicka, M. (2012). A new triterpene from Scorzonera latifolia (Fisch. and Mey.) DC. Natural Product Research, 26(20), 1892-1897. doi:10.1080/14786419.2011.625644
Acıkara, Ö. B., Ergene Öz, B., Bakar, F., Saltan Çitoğlu, G., \& Nebioğlu, S. (2017). Evaluation of Antioxidant Activities and Phenolic Compounds of Scorzonera latifolia (Fisch. \& Mey.) DC. Collected from Different Geographic Origins in Turkey. The Turkish Journal of Pharmaceutical Sciences, 14(2), 179-184. doi:10.4274/tjps.57070

- $\quad$ Athmouni, K., Belghith, T., Bellassouad, K., Feki, A. E., \& Ayadi, H. (2015). Effect of extraction solvents on the biomolecules and antioxidant properties of Scorzonera undulata (Asteraceae): Application of factorial design optimization phenolic extraction. Acta Scientiarum Polonorum, Technologia Alimentaria, 14(4), 313-330. doi:10.17306/j.afs.2015.4.32

- Bader, A., De Tommasi, N., Cotugno, R., \& Braca, A. (2011). Phenolic compounds from the roots of Jordanian viper's grass, Scorzonera judaica. Journal of Natural Products, 74(6), 1421-1426. doi:10.1021/ np200143s

- $\quad$ Baykan-Erel, S., Bedir, E., Khan, I. A., \& Karaalp, C. (2010). Secondary metabolites from Centaurea ensiformis P.H. Davis. Biochemical Systematics and Ecology, 38(5), 1056-1058. doi:https://doi. org/10.1016/j.bse.2010.09.004

- Baytop, T. (1999). Türkiye'de Bitkilerle Tedavi Geçmişte ve Bugün (Therapy with medicinal plants in Turkey). İstanbul: Nobel Tip.

- Benzie, I. F. F., \& Strain, J. J. (1996). The Ferric Reducing Ability of Plasma (FRAP) as a Measure of "Antioxidant Power": The FRAP Assay. Analytical Biochemistry, 239(1), 70-76. doi:http://dx.doi. org/10.1006/abio.1996.0292

- Brand-Williams, W., Cuvelier, M. E., \& Berset, C. (1995). Use of a free radical method to evaluate antioxidant activity. Food Science Technology (London), 28(1), 25-30. doi:10.1016/S00236438(95) $80008-5$

- $\quad$ Chang, S. W., Kim, K. H., Lee, I. K., Choi, S. U., Ryu, S. Y., \& Lee, K. R. (2009). Phytochemical constituents of Bistorta manshuriensis. Natural Products Sciences, 15(4), 234-240.

- CLSI. (2000). Reference Method for Broth Dilution Antifungal Susceptbility Testing of Yeasts; Approved Standart M27-A NCCLS. Wayne, Pennsylvania: CLSI.

- CLSI. (2006). Methods for dilution antimicrobial susceptibility tests for bacteria that grow aerobically: Approved Standard M7A5. Wayne, PA: CLSI.

- Coşkunçelebi, K., Makbul, S., Gültepe, M., Okur, S., \& Güzel, M. E. (2015). A conspectus of Scorzonera s.l. in Turkey. Turkish Journal of Botany, 39, 76-87. doi:10.3906/bot-1401-10

Dalar, A., Mukemre, M., Unal, M., \& Ozgokce, F. (2018). Traditional medicinal plants of Ağrı Province, Turkey. Journal of Ethnopharmacology, 226, 56-72. doi:https://doi.org/10.1016/j.jep.2018.08.004 Duh, P. D., Tu, Y. Y., \& Yen, G. C. (1999). Antioxidant Activity of Water Extract of Harng Jyur (Chrysanthemum morifolium Ramat). LWT - Food Science Technology, 32(5), 269-277. doi:http://dx.doi. org/10.1006/fstl.1999.0548

- Harkati, B., Akkal, S., Bayat, C., Laouer, H., \& Franca, M. G. D. (2010). Secondary metabolites from Scorzonera undulata ssp. deliciosa (Guss.) Maire (Asteracae) and their antioxidant activities. Records of Natural Products, 4(3), 171-175.

- Kokoska, L., \& Janovska, D. (2009). Chemistry and pharmacology of Rhaponticum carthamoides: A review. Phytochemistry, 70(7), 842-855. doi:https://doi.org/10.1016/j.phytochem.2009.04.008 Koyuncu, O., Yaylacı, Ö. K., \& Kuş, G. (2014). Taxonomical Studies on Endemic Scorzonera pygmaea var. pygmaea and var. nutans Stat. Nov. (Asteraceae) From Turkey. Pakistan Journal of Botany, 46(2), 555-563.

Lende, A. B., Kshirsagar, A. D., Deshpande, A. D., Muley, M. M., Patil, R. R., Bafna, P. A., \& Naik, S. R. (2011). Anti-inflammatory and analgesic activity of protocatechuic acid in rats and mice. Inflammopharmacology, 19(5), 255. doi:10.1007/s10787-011-0086-4 
- Liang, N., \& Kitts, D. D. (2016). Role of Chlorogenic Acids in Controlling Oxidative and Inflammatory Stress Conditions. Nutrients, 8(1), 16. doi:10.3390/nu8010016

- Milella, L., Bader, A., De Tommasi, N., Russo, D., \& Braca, A. (2014). Antioxidant and free radical-scavenging activity of constituents from two Scorzonera species. Food Chemistry, 160, 298-304. doi:http://dx.doi.org/10.1016/j.foodchem.2014.03.097

- Nasseri, M. A., Sharifi Bigy, S., Allahresani, A., \& Malekaneh, M. (2015). Assessment of Antioxidant Activity, Chemical Characterization and Evaluation of Fatty Acid Compositions of Scorzonera paradoxa Fisch and C. A. Mey. Jundishapur Journal of Natural Pharmaceutical Products, 10(4), e19781. doi:10.17795/jjnpp-19781

- $\quad$ Nguyen, X. H. T., Juvik, O. J., Øvstedal, D. O., \& Fossen, T. (2014). 6-Carboxydihydroresveratrol 3-O- $\beta$-glucopyranoside - A novel natural product from the Cretaceous relict Metasequoia glyptostroboides. Fitoterapia, 95, 109-114. doi:https://doi.org/10.1016/j. fitote.2014.03.001

- $\quad$ Nishikimi, M., Rao, N. A., \& Yagi, K. (1972). Occurrence of superoxide anion in the reaction of reduced phenazine methosulfate and molecular oxygen. Biochemical and Biophysical Research Communications, 46(2), 849-854. doi:10.1016/S0006-291X(72)80218-3

- Paraschos, S., Magiatis, P., Kalpoutzakis, E., Harvala, C., \& Skaltsounis, A. L. (2001). Three new dihydroisocoumarins from the Greek endemic species Scorzonera cretica. Journal of Natural Products, 64(12), 1585-1587. doi:10.1021/np0103665

- Phaniendra, A., Jestadi, D. B., \& Periyasamy, L. (2015). Free radicals: properties, sources, targets, and their implication in various diseases. Indian journal of clinical biochemistry: IJCB, 30(1), 11-26. doi:10.1007/s12291-014-0446-0

- Polat, R. (2019). Ethnobotanical study on medicinal plants in Bingöl (City center) (Turkey). Journal of Herbal Medicine, 16, 100211. doi:https://doi.org/10.1016/j.hermed.2018.01.007

- Re, R., Pellegrini, N., Proteggente, A., Pannala, A., Yang, M., \& RiceEvans, C. (1999). Antioxidant activity applying an improved ABTS radical cation decolorization assay. Free Radical Biology and Medicine, 26(9/10), 1231-1237. doi:10.1016/S0891-5849(98)00315-3

- Sarı, A. (2010). Two new 3-benzylphthalides from Scorzonera veratrifolia Fenzl. Natural Product Research, 24(1), 56-62. doi:10.1080/14786410902800699

- Sarı, A. (2012). Phenolic compounds from Scorzonera latifolia (Fisch. \& Mey.) DC. Natural Product Research, 26(1), 50-55. doi:10 $.1080 / 14786419.2010 .533666$

- Sarı, A., Özbek, B., \& Özgökçe, F. (2009). Antimicrobial activities of two Scorzonera species growing in Turkey. Asian Journal of Chemistry, 21(6), 4785-4788.

- Sarı, A., Şahin, H., Özsoy, N., \& Özbek Çelik, B. (2019). Phenolic compounds and in vitro antioxidant, anti-inflammatory, antimicrobial activities of Scorzonera hieraciifolia Hayek roots. South African Journal of Botany, 125, 116-119. doi:https://doi.org/10.1016/j. sajb.2019.07.009

- Sarı, A., Zidorn, C., Ellmerer, E. P., Özgökçe, F., Ongania, K.-H., \& Stuppner, H. (2007). Phenolic Compounds from Scorzonera tomentosa L. Helvetica Chimica Acta, 90, 311-317.

- $\quad$ Singh, K. N., \& Lal, B. (2008). Ethnomedicines used against four common ailments by the tribal communities of Lahaul-Spiti in western Himalaya. Journal of Ethnopharmacology, 115(1), 147159. doi:https://doi.org/10.1016/j.jep.2007.09.017
Slinkard, K., \& Singleton, V. L. (1977). Total phenol analysis: automation and comparison with manual methods. American Journal of Enology and Viticulture, 28(1), 49-55.

Şahin, H., Sarı, A., Özsoy, N., Özbek Çelik, B., \& Koyuncu, O. (2020). Two new phenolic compounds and some biological activities of Scorzonera pygmaea Sibth. \& Sm. subaerial parts. Natural Product Research, 34(5), 621-628. doi:10.1080/14786419.2018.1493585

Şenkardeş, I., Bulut, G., Doğan, A., \& Tuzlacı, E. (2019). An Ethnobotanical Analysis on Wild Edible Plants of the Turkish Asteraceae Taxa. Agriculturae Conspectus Scientificus, 84(1), 17-28.

Toshikawa, M., Uchida, E., Chatani, N., Kobayashi, H., Naitoh, Y., Okuno, Y., ... Murakami, N. (1992). Thunberginols C,D and E, New Antiallergic and Antimicrobial Dhiydroisocoumarins and Thunberginol G 3'-O-Glucoside and (-)-Hydrangenol 4'-O-Glucoside, New Dhydroisocoumarin Glycosides from Hydrangea dulcis Folium. Chemical and Pharmaceutical Bulletin, 40(12), 3352-3354. doi:10.1248/cpb.40.3352

- Tsevegsuren, N., Edrada, R., Lin, W., Ebel, R., Torre, C., Ortlepp, S., ... Proksch, P. (2007). Biologically active natural products from Mongolian medicinal plants Scorzonera divaricata and Scorzonera pseudodivaricata. Journal of Natural Products, 70, 962-967.

- Vitaglione, P., Donnarumma, G., Napolitano, A., Galvano, F., Gallo, A., Scalfi, L., \& Fogliano, V. (2007). Protocatechuic Acid Is the Major Human Metabolite of Cyanidin-Glucosides. The Journal of Nutrition, 137(9), 2043-2048. doi:10.1093/jn/137.9.2043

- Wang, Y., Wray, V., Tsevegsuren, N., Lin, W. H., \& Proksch, P. (2012). Phenolic Compounds from the Mongolian Medicinal Plant Scorzonera radiata. Zeitschrift Fur Naturforschung Section C-a Journal of Biosciences, 67(3-4), 135-143.

Yang, Y. J., Liu, X., Wu, H. R., He, X. F., Bi, Y. R., Zhu, Y., \& Liu, Z. L. (2013). Radical scavenging activity and cytotoxicity of active quinic acid derivatives from Scorzonera divaricata roots. Food Chemistry, 138(2-3), 2057-2063. doi:10.1016/j.foodchem.2012.10.122

- Yang, Y. J., Yao, J., Jin, X. J., Shi, Z. N., Shen, T. F., Fang, J. G., ... Zhu, Y. (2016). Sesquiterpenoids and tirucallane triterpenoids from the roots of Scorzonera divaricata. Phytochemistry, 124, 86-98. doi:http://dx.doi.org/10.1016/j.phytochem.2016.01.015

Zhu, X., Dong, X., Wang, Y., Peng, J., \& Luo, S. (2005). Phenolic compounds from Viburnum cylindricum. Helvetica Chimica Acta, 88(2), 339-342. doi:10.1002/hlca.200590017

Zidorn, C., Ellmerer-Müller, E. P., \& Stuppner, H. (2000). Tyrolobibenzyls - Novel secondery metabolites from Scorzonera humilis. Helvetica Chimica Acta, 83, 2920-2925.

Zidorn, C., Lohwasser, U., Pschorr, S., Salvenmoser, D., Ongania, K.-H., Ellmerer, E. P., . . Stuppner, H. (2005). Bibenzyls and dihydroisocoumarins from white salsify (Tragopogon porrifolius subsp. porrifolius). Phytochemistry, 66(14), 1691-1697. doi:10.1016/j.phytochem.2005.05.004

Zidorn, C., Spitaler, R., Ellmerer-Müller, E.-P., Perry, N. B., Gerhäuser, C., \& Stuppner, H. (2002). Structure of Tyrolobibenzyl D and Biological Activity of Tyrolobibenzyls from Scorzonera humilis. Zeitschrift für Naturforschung C, 57(7-8), 614-619. doi:10.1515/ znc-2002-7-811 